METZLER

LEXIKON RELIGION 


\section{METZLER \\ LEXIKON RELIGION}

Gegenwart - Alltag - Medien

Band 3:

Paganismus - Zombie

herausgegeben von

Christoph Auffarth, Jutta Bernard Hubert Mohr

unter Mitarbeit von

Agnes Imhof und Silvia Kurre 
Die Deutsche Bibliothek - CIP-Einheitsaufnahme

Metzler-Lexikon Religion : Gegenwart - Alltag - Medien / hrsg. von Christoph Auffarth . . . unter Mitarb. von Agnes Imhof und Silvia Kurre. - Stuttgart ; Weimar : Metzler

ISBN 978-3-476-01678-2

Bd. 3. Paganismus - Zombie. -2000

ISBN 978-3-476-01553-2

ISBN 978-3-476-01553-2

ISBN 978-3-476-03704-6 (eBook)

DOI 10.1007/978-3-476-03704-6

Dieses Werk einschließlich aller seiner Teile ist urheberrechtlich geschützt. Jede Verwertung außerhalb der engen Grenzen des Urheberrechtsgesetzes ist ohne Zustimmung des Verlages unzulässig und strafbar. Das gilt insbesondere für Vervielfältigungen, Übersetzungen, Mikroverfilmungen und die Einspeicherung und Verarbeitung in elektronischen Systemen.

(C) 2000 Springer-Verlag GmbH Deutschland

Ursprünglich erschienen bei J.B. Metzlersche Verlagsbuchhandlung und Carl Ernst Poeschel Verlag GmbH in Stuttgart 2000 